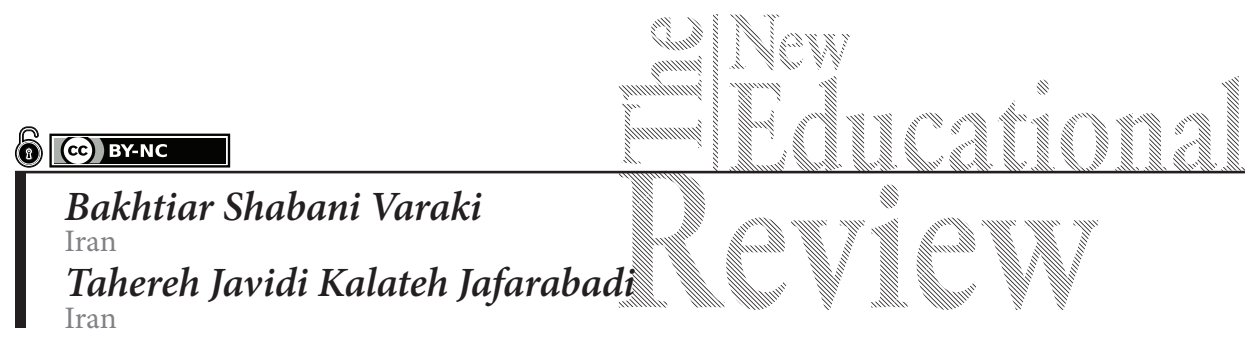

\title{
Educational Research Methodology Inspired by the Theory of Enaction
}

DOI: $10.15804 /$ tner.2020.62.4.12

\begin{abstract}
A theory of cognition and an interdisciplinary research program so-called enactivism put forward by Varela, Thompson, and Rosch since their book titled: "The Embodied Mind: Cognitive Science and Human Experience had been published in 1991. The theory and research program proposed in this book can be explicated in terms of eight significant themes including autopoiesis, sense-making, emergence, experience, embodied mind, embedded mind, enacted mind and the extended mind. This paper is an interpretation of the theory of enaction as a platform to educational research methodological reform. So it is argued that the non-reductionistic enactive approach is the promising arena for addressing educational research methodology so that circulation between first- and third-personal phenomena makes sense across a range of objective and subjective issues that mixed methodologists want to deal.
\end{abstract}

Key words: Neuro-phenomenology, theory of enaction, circular research methodology, educational phenomena and activity

\section{Introduction}

Mixed methods research, as the third methodological movement (Creswell, 2011,273 ), had a rapid growth and became a formal methodology in a variety of discipline areas including psychology, education, and social science through the 
2000s (Cameron, 2010). The main reasons for mixed methods could be conceptualized in:

Two types of considerations. The practical level, mixing the arguments related to the use of sampling, data collection, and data analysis techniques and the theoretical level, the reasons entail the pragmatic, the false duality and the warrant-through-triangulation arguments. (Shabani Varaki et al., 2015, 28-29)

However, mixed-methods opponents and proponents argued that both arguments are controversial and problematic. They classified the crises in different ways: four levels of problems; "philosophical, cultural, psychological, and practical" (Mingers, 2001, 247), two-level of problems practical and paradigmatic (Shabani Varaki et al., 2015, 29) and "four major crises or challenges to mixed methods research: representation, legitimation, integration, and politics" (Onwuegbuzie and Collins, 2007, 282). Since several mixed-methods proponents argue "the problems are not insurmountable" (Mingers, 2001,247), the opponents believe that we need to have an alternative to avoid the issues and the methodological trilingualism (Shabani Varaki et al., 2015). This paper will explore the alternative through the theory of enaction as a conceptual framework and methodology. Enactivism tends to cover the issues and challenges with the mixed method and replace trilingualism with unilingualism. Enaction theory will be explicated in terms of eight significant themes including autopoiesis, sense-making, emergence, experience, embodied mind, embedded mind, enacted mind and the extended mind. The paper concludes with options for a non-reductionist, unbroken coincidence, amalgamated and an ecumenical approach to the world with an inter-subjective interaction; self-other co-determination; reciprocal causal interaction, non-linearity, beyond equilibrium.

\section{Neuro-phenomenology: the origin of enaction}

Neuro-phenomenology as a neuroscientific research program, in contrast to the neuro-philosophy and eliminativist position rooted in analytic philosophy (Churchland, 2002), has derived from the continental tradition of phenomenological philosophy, the particular phenomenology of Husserl's philosophy (Varela, 1996). While neuro-philosophy wants to reduce mind into the brain, the neuro-phenomenology aims to recognize mind, brain, body and environment in the lineage of cognitive science and the Husserl's phenomenological legacy for 
direct experience (Rowlands, 2010). Therefore, this program invites us to consider both physiological and experiential data in every scientific study of cognition. Whereas the previous program tries to explain how the brain works in itself, neuro-phenomenology tries to consider perception, emotion and all cognitive events associated with brain, body, and environment.

Furthermore, although neuro-phenomenology focuses on the rigor oriented investigation of cognition, it puts forward this idea that it is required to overcome the onlooker attitude about the experience. This account is phenomenological, which can provide an experiential validation for the rigor biological oriented examination and constrain the interpretation of empirical data (Lutz \& Thompson, 2003). Accordingly, the two domains of discourse (the physiological and the phenomenological) are circularly intertwined (Lutz, 2002).

This approach is a unique synthesis of cutting-edge neurobiology, philosophy, and cognitive science that has implications for our understanding of human consciousness. (Hallowell, 2009, 144)

Indeed, there are two crucial advances in the development of cognitive science: "the embodied turn" and "the interactive turn". The embodied turn refers to the neurobiological, and the interactive turn refers to the social foundations of the enaction. Therefore, the enactive approach is a response to false dualisms "between brain and body" and "between individual and others" (Kyselo, 2014). Moreover, the embodied turn seeks to explain that cognition not just in the brain and no longer restricted to third-person operational descriptions, but in "the somatic contexts of the organism as a whole". Therefore, enaction favours an embodied cognition to neural dynamics which embedded in "cycles of organismic regulation of the entire body; cycles of sensorimotor coupling between organism and environment; cycles of intersubjective interaction" (Lutz \& Thompson, 2003, 41). Accordingly, neuro-phenomenology is an alternative approach which believes the controversy between reductionism and holism is false and the correct position is one that is similar to yin and yang, in Chinese philosophy, the two domains of explanation are complementary and amalgamated.

Reductionism implies attention to a lower level, while holistic implies attention to a higher level. These are intertwined in any satisfactory description: and each entails some loss relative to our cognitive preferences, as well as some gain ... there is no whole system without an interconnection of its parts, and there is no whole system without an environment. (Rudrauf et al., 2003, 40) 
Therefore, we need to set a comprehensive account to move towards credible knowledge about educational phenomena continually. In the following section, rooted in the neuro-phenomenology project, we scrutinize how the theory of enaction could be recognized as comprehensive view of educational research methodology.

\section{Theory of Enaction: Major themes}

Theory of enaction is a new approach within the field of cognitive science focusing on the ontological and epistemological underlying cognition and cognitive science which is presented by Maturana and Varela (1980) and Varela, Thompson and Rosch (2016). The theory is a departure point of representationalism and the computer model of cognition, and underlying cognitive science, phenomenology, and Buddhism, it focuses on "the continuity between life and mind" (Stewart et al., 2010) as an alternative to overcome the Cartesian dualism.

Enaction suggests a dynamic process of world-constitution that is always intimately linked to a particular bodily identity and situated within a greater field of interpenetrating relationships. (Malkemus, 2012, 201)

Thereupon Varela, Thompson, and Rosch (2016) emphasize that there is a significant difference between the crystalline system such as the game of chess and the less well-defined domain like driving world. Although in the driving space we can recognize some discrete items in contrast with the game of chess the limits of this space are not clearly defined and so the driving world is strongly depended on both knowing-that (acquired skills) and knowing-how (the continuous use of non-specific background). In other words, Maturana and Varela $(1987,26)$ believe that: "All doing is knowing, and all-knowing is doing". Thus "the universal nature of doing in cognition" (Maturana and Varela, 1987, 28), indicates that there is no gap between knowing, being and acting. In this paper, we examine the framework in light of the eight intertwined key concepts:

\section{Autopoiesis}

Autopoiesis is a term invented by Maturana while talking with Varela and Jose Bulnes, to describe "the central feature of the organization of the living, which is 
autonomy." it is "a word that could mean what takes place in the dynamic of the autonomy proper to living system" (Maturana and Varela, 1980, xvii). Thompson (Thompson, 2005, 407-408) described the critical ideas of autopoiesis as follows:

The first idea is that living beings are autonomous agents that actively generate and maintain their identities, and thereby enact or bring forth their own cognitive domains.

The second idea is that the nervous system is an autonomous system: it actively generates and maintains its own coherent and meaningful patterns of activity ... The nervous system does not process information in the computational sense but creates meaning.

The third idea is that cognition is a form of embodied action. Cognitive structures and processes emerge from recurrent sensorimotor patterns of perception and action. Sensorimotor coupling between organism and environment modulates but does not determine, the formation of endogenous, dynamic patterns of neural activity, which in turn inform sensorimotor coupling.

The fourth idea is that a cognitive being's world is not a pre-specified, external realm, represented internally by its brain, but a relational domain enacted or brought forth by that being's autonomous agency and mode of coupling with the environment.

Accordingly, the autopoietic system is a network characterized by a continuous interaction between its components. This interaction has two functions; the production of the components and the existence of the system. In other words, when a property of a component in a system changes, other components upgrade their properties and keep the system alive. We believe that this idea links the enactive approach to educational research because both provide the same circumstances that cognition comes through a constitutive relation to the environment. In this respect, we argue that educational research is a dynamic study of the changing world, and it could be considered as a medium which is changing continuously. A researcher and researched will work all together as agents at the medium and super-complex system so-called autopoietic.

\section{Sense-Making}

In a seminal article published in 1997, entitled "Patterns of life: Intertwining identity and cognition," Varela stated the central idea of his theory of autonomy in the following way: 
I want to start by declaring that I think that understanding of organisms and the living is possible, that defining these terms in a satisfactory manner is not a utopian dream, and that we even have a good deal of the road already charted. However, this is under a fundamental condition: that the autonomy of the living is highlighted instead of forgotten, as it has been.

To highlight autonomy means essentially to put at center of the stage two interlinked propositions.

Proposition 1: Organisms are fundamentally a process of constitution of an identity. Proposition 2: The organism's emergent identity gives, logically and mechanistically, the point of reference for a domain of interactions. (Varela, 1997, 73)

He illustrated the two propositions in figure (1) and emphasized that they are complementary.

Accordingly, he believes that lived cognition is an activity that relies on an autopoietic system, a lived and survival organization that requires knowledge to make sense of its environment. He called this activity as "sense-making". Indeed, for Varela, "notion of sense-making, assumes that the whole organism is a vehicle of meaning" (Stewart, Gapenne and Di Paolo, 2010, 147), and so "sense-making is also world-making", because any organisms, including school, enact a world for its survival and continuity (Malkemus, 2012, 205-206).

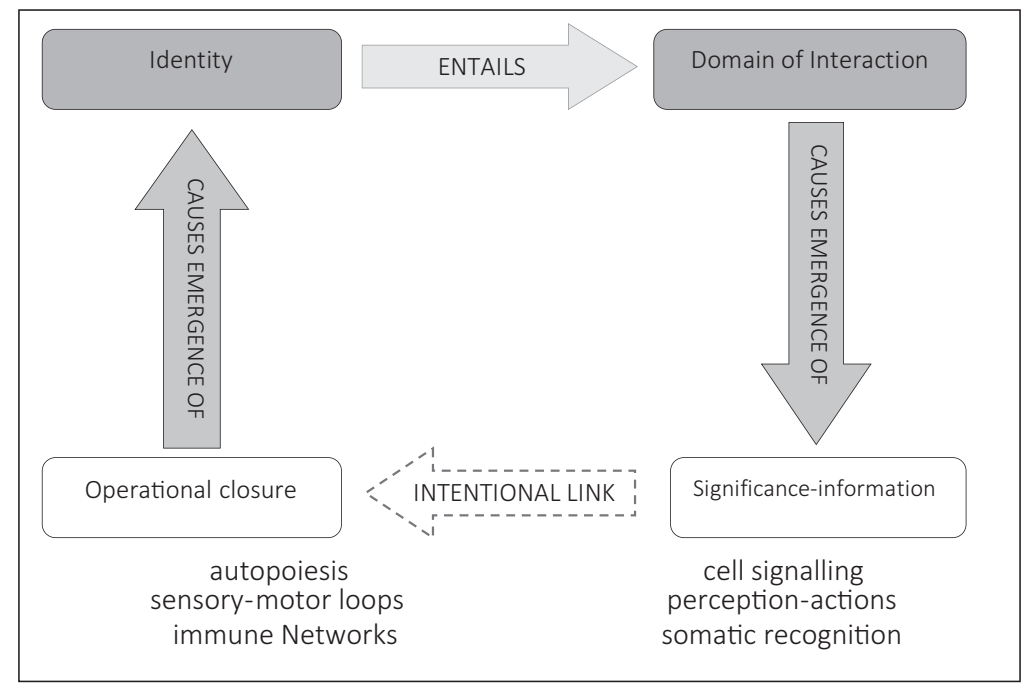

Figure 1. The two key intertwined concepts to account for the autonomy of the living (Varela, 1997, 74) 


\section{Emergence}

Thompson (2007) argues that the theory of enaction is a way of thinking about emergence. The dynamic co-emergence of cognition means that cognition emerges from the interaction between brain, body and environment.

"Dynamic co-emergence means that a whole not only arise from its parts, but the parts also arise from the whole. Parts and whole co-emerge and mutually specify each other. A whole cannot be reduced to its parts, for the parts cannot be characterized independently of the whole, conversely, the parts cannot be reduced to the whole, for the whole cannot be characterized independently of the parts". (Thompson, 2007, 38)

Therefore, the central idea of emergence theory forms a background to define and explain educational activity as emergent phenomena which require an enactive approach to educational research.

The theory characterizes emergent phenomena by five significant properties, radical novelty, coherence, macro level, dynamical and ostensive; all these are demonstrated in the table (1):

Table 1. Five properties of emergent phenomena (Goldstein, 1999, 50).

\begin{tabular}{ll}
\hline \multicolumn{1}{c}{ Properties } & \multicolumn{1}{c}{ Meaning } \\
\hline radical novelty & $\begin{array}{l}\text { not previously observed } \\
\text { not able to be anticipated in their full richness before they show them- } \\
\text { selves } \\
\text { not deducible from micro-level components }\end{array}$ \\
\hline coherence & $\begin{array}{l}\text { appear as integrated wholes } \\
\text { spanning the separate micro-level components into a macro-level } \\
\text { unity }\end{array}$ \\
\hline macro-level & the locus of emergent phenomena occurs at a global or macro level \\
\hline dynamical & $\begin{array}{l}\text { not pre-given wholes } \\
\text { associated with the arising of new attractors in a complex system } \\
\text { a system evolves over time }\end{array}$ \\
\hline ostensive & $\begin{array}{l}\text { recognized by showing themselves } \\
\text { ostensibly recognized }\end{array}$ \\
\hline
\end{tabular}

Accordingly, Goldstein (1999) explains that the construct of emergence requires focusing on the across-system organization and an interplay between the parts and the whole to study complex or self-organization systems. Additionally, "emergence follow more of a continuum than a discrete jump from part to whole (Figure 2)". (p. 50). 
Figure 2. Continuum of emergence explanations (Goldstein, 1999, 51)

The concept of "whole" in emergent phenomena defers from the idea of gestalt; "the whole is greater than the sum of the parts" (Ehrenfeld, 2008, 103). Gestalt is a non-dynamical idea that refers to a pre-given whole. However, emergence is a dynamic idea that is associate with the originating, not pre-given attractors. Indeed, emergence characterizes a quantitative and qualitative change by bifurcating a dynamic system.

\section{Experience}

The experience explained here comes from a holographic view of life. It is connected with both first-person subjective data - Participants' own consciousness - and third-person data - of the structure and function of the brain and body. Both kinds of data have "equal status in demanding full attention and respect for their specificity" (Varela, 1996, 343). Accordingly, experience "becomes a guiding force in a dialogue between phenomenology and science, resulting in an ongoing pragmatic circulation and mutual illumination between the two" (Stewart et al. 2010, 43). Varela, Thompson and Rosch place this sense of experience at the center of enactive theory, methodologically. Furthermore, they introduce the phenomenological method into the experimental lab.

The new sciences of mind need to enlarge their horizon to encompass both lived human experience and the possibilities for transformation inherent in human experience. Ordinary, everyday experience, on the other hand, must enlarge its horizon to benefit from the insights and analyses that are distinctly wrought by the sciences of mind. (Varela, Thompson and Rosch, 2016, 15)

For enactive theory, the nature of direct experience is irreducible, ordinary, everyday, inter-subjectively available, and describable. Indeed, it is irreducible to components and avoids over-emphasizing any particular physical, mental, emo- 
tional, collaborative, or other modality. So We need to invite all dimensions of experience to engage in the research process's unfolding by addressing the interior and exterior.

\section{Embodied Mind}

Embodied mind, rooted in Martin Heidegger and Maurice Merleau-Ponty's works, means being connected to the body and at the same time the body influences the mind. The process of consciousness goes beyond the mere brain and is not confined to cortices. Although the brain is an integral part of the body, the mind has specific experiences of the world due to being in the body with a particular structure and function. In other words, the body, because of its structure and function, determines our experiences in the world.

Wilson and Foglia (2011) summarize four quotes from; McNeill 1992, O’Regan and Noë 2001, Rizzolatti and Craighero 2004 and Donald 1991) as evocative examples of phenomena; gesturing, visioning, using mirror neurons and performing cognitive tasks that have motivated embodied mind.

\footnotetext{
"We typically gesture when we speak to one another, and gesturing facilitates not just communication but language processing itself (McNeill 1992). Vision is often action-guiding, and bodily movement and the feedback it generates are more tightly integrated into at least some visual processing than has been anticipated by traditional models of vision (O’Regan and Noë 2001). There are neurons, mirror neurons, that fire not only when we undertake an action, but do so when we observe others undertaking the same actions (Rizzolatti and Craighero 2004). We are often able to perform cognitive tasks, such as remembering, more effectively by using our bodies and even parts of our surrounding environments to off-load storage and simplify the nature of the cognitive processing". (Donald 1991)
}

This idea is a refutation of Descartes' when he claimed; "there is a great difference between a mind and a body in that a body, by its very nature, is always divisible. On the other hand, the mind is utterly indivisible (Descartes and Cress, 1998, 100-101)". Therefore, by considering an example of the sense of hearing, we can explain that if we had another ear like a bat's ear, we would hear and experience sound differently. The body creates a soft constraint on the nervous system so the mind cannot process that information not transmitted by the form and raw material of the body, and the command of movement issued by the brain cannot be physically transferred to 
the body. Therefore, perception depends on the body, located in a specific time and place. The mind, therefore, is not a Cartesian abstract object of thought. Physical and chemical processes are not merely cerebral, but consciousness in a body with specific capabilities recognizes the world around it and reveals the world to us through the body filter we have and the things we can do.

\section{Embedded Mind}

Embodiment means locality of the mind, and being in the body, embedded means locality of the body in terms of being in the world. For example, when we use the word "in" to say that water is "in" a glass, or that the color is "in" a can, "in" here means being and being in a pre-given body in another pre-given body, but there is no connection between the two. Nevertheless, using "in" to say the root is "in" the soil, or say that the body is the "in" the world, the two can no longer be separated. The root and soil are coexistent. The growth of a plant root affects the surrounding soil and vice versa. Both are the generic composition of the plant.

Varela, Rosch and Thompson taking an example of color study, discussed the differences between Chicken position and egg position: by the Chicken position they mean "The world out there has pre-given properties. These exist prior to the image that is cast on the cognitive system, whose task is to recover them appropriately (whether through symbols or global sub-symbolic states). By Egg position, they mean "The cognitive system projects its own world, and the apparent reality of this world is merely a reflection of internal laws of the system". They explain that we should bypass the logical geography of inner versus outer, by embracing the middle of the two chicken and egg extremes. We have seen that colors are not "out there" independent of our perceptual and cognitive capacities. We have also seen that colors are not "in here" independent of our surrounding biological and cultural world. Contrary to the objectivist view, color categories are experiential; contrary to the subjectivist view, color categories belong to our shared biological and cultural world. Thus color as a study case enables us to appreciate the obvious point that chicken and egg, world and perceiver, specify each other ( Varela, Rosch and Thompson, 1993, 172)".

Therefore, our experience of the educational activity has such an orientational structure not as the result of the objective direction of "out-there" and not as a result of our cognitive system projection of in-here. Instead because of the golden mean position, understanding educational phenomena requires to appre- 
ciate the Scylla of cognition (recovering what is outer) and Charybdis of cognition (projecting what is inner) evolved together.

So embedded mind intertwined with the embodied mind. Embodiment requires to appreciate human body with its various sensorimotor capacities that are a significant source of their experience, and the sensorimotor capabilities are embedded in a more encompassing physical and cultural environment (Varela et al., 2016).

\section{Enacted Mind}

Enactive refers to an assumption that the mind depends on the activity of the agent. Moreover, the activity of the agent is done by filtering the body and within the capabilities of the body.

A cognitive being's world is not a pre-specified, external realm, represented internally by its brain, but a relational domain enacted or brought forth by that being's autonomous agency and mode of coupling with the environment. (Thompson, 2005, 407)

So, the mind is in the body; the body is within the environment; the mind relates to the world through sensorimotor activities. That is, due to the recurrent sensorimotor activities concerning the world. These activities affect the world, the body, the mind and consciousness, and cognitive patterns. Indeed, the mind is formed by a recurrent sensorimotor pattern.

Cognitive structures and processes emerge from recurrent sensorimotor patterns of perception and action. (Thompson, 2005, 407)

The sense of sight is an example. It has been traditionally said that man is a passive creature whose visual stimulus strikes his eyes and is worked on by brain activity, and a command is issued that allows us to see that object. This process is only a small part of the operation of the mind, and there is also the reverse flow, that is, if there are no sensory-motor rules and movement and action and attention, we do not see anything. 


\section{Extended Mind}

This idea was first proposed by Clark and Chalmers (Clark \& Chalmers, 1998) in an article entitled "Expanded Mind." They did not accept the demarcations of skin and skull, and so proposed an alternative so-called; active externalism. They argue that in driving cognitive processes, the environment has an active role.

"The human organism is linked with an external entity in a two-way interaction, creating a coupled system that can be seen as a cognitive system in its own right. All the components in the system play an active causal role, and they jointly govern behavior in the same sort of way that cognition usually does. If we remove the external component, the system's behavioral competence will drop, just as it would if we removed part of its brain. Our thesis is that this sort of coupled process counts equally well as a cognitive process, whether or not it is wholly in the head"'. (Clark and Chalmers, 1998, 8-9)

The mind does not stop at the head or skin of the body. At the beginning of this article, they ask, where the mind stops and the world begins. To answer this question, they took an example of someone who has Alzheimer's and the benefit of the booklet as a reminder. In this case, the pamphlet can be considered as part of the mechanisms of the brain. Therefore, the mind is not limited to the body, and cognition arises from the circular cooperation between mind, body and environment.

In brief, enacted consists of "perceptually guided action" and "cognitive structures" emerge from the recurrent sensorimotor patterns that enable action to be perceptually guided (Varela, Thompson and Rosch, 2016, 173).

\section{Final remark: macro strategies of the circular methodology}

This paper is an interpretation of the theory of enaction as a platform to educational research methodological reform. So it is argued that the non-reductionistic enactive approach is the promising arena for addressing educational research methodology so that circulation between first- and third-personal phenomena makes sense across a range of objective and subjective issues that mixed methodologists want to deal. Accordingly, we consider research method as a strategic framework consisting of macro and micro strategies. Macro strategies mean guiding principles derived from the theory of enaction and micro strategies refer to 
context-oriented issues related to research procedures. The strategic framework is consistent with our "para-quantitative methodology" (Shabani Varaki et al., 2015), and also has the potential to transcend the limitations of the quantitative mono method and qualitative mono method and the concept of pre-given Pushmi-pullyu methodology with two approaches at opposing origins and ends, trying to mix two incommensurable methods.

Thus, as shown in figure (3), we offer eight macro strategies to conceptualize the circular methodology derived from the theory of enaction as guiding principles, and a general plan, based on which researchers will be able to study an educational phenomenon using first-person, and third-person data together.

1. Autopoiesis; this strategy means that the researcher and the researched are parts of the autonomy dynamics proper to a living system. They are autonomous agents that actively generate and maintain their identities. Moreover, research methods are processes that emerge from recurrent sensorimotor patterns of perception and action which coupling between organism and environment modulates.

2. Sense-making; this strategy means that in virtue of being autonomous agents, the researcher and the researched can be considered as sense-making systems. So they are practicing related to environment. Being-in-the-world that is entirely different from that of water being in a glass. Accordingly, research is a process of sense-making in interaction and a way to the emergence of important information and human identity as well. Therefore, the whole organism (including the researcher/the researched) is a vehicle of meaning.

3. Emergence; this strategy involves five significant properties including radical novelty, coherence, macro level, dynamical and ostensive of educational phenomena. It requires focusing on the across-system organization and an interplay between the parts and the whole to study complex or self-organized systems.

4. Experience; this strategy intertwined with both first-person data - Participants' own consciousness - and third-person data - of the structure and function of the brain and body. So it requires to synthesize first-person data with experimental methodology in educational research. This strategy avoids over-emphasizing any particular physical, mental, emotional, collaborative, or other modality in educational research.

5. Embodied mind; this strategy means being connected to the body, and at the same time, the body influences the mind. Although the brain is an integral part of the body, cognition is not confined to cortices. So we, as researchers, 
should consider the contribution of the body with a particular structure and function to understand educational phenomena.

6. Embedded mind; this strategy means locality of the body in terms of being in the world. It intertwined with the embodied mind. Embodiment requires to appreciate the human body with its various sensorimotor capacities that are a significant source of their experience, and the sensorimotor capabilities are embedded in a more encompassing physical and cultural environment. Therefore, educational research inspired by this strategy should be considered situational.

7. Enacted mind; this strategy refers to the activity of the agent, which is done by filtering the body. So, the mind is in the body; the body is within the environment; the mind relates to the world through sensorimotor activities. Through this strategy, educational researcher requires enlightened eyes to understand the educational world.

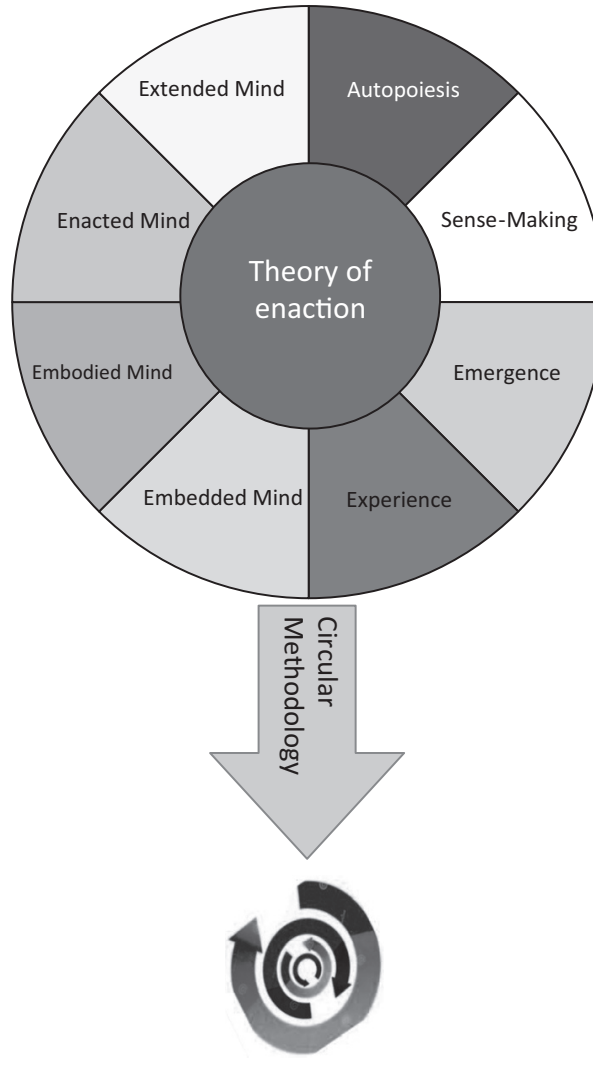

Figure 3. Macro-strategies of Research method inspired by the theory of enaction 
8. Extended mind; this strategy means the possibility of cognitive extension. Therefore, the human mind extended throughout the living body and the world. As educational researchers, we need to consider the expanded cognitive system, which is beyond the body's boundary. The expanded cognitive system consists of the body, and everything (external to the body's boundary) has a function in the sense-making interaction with the environment.

\section{Acknowledgements}

This research was supported by the Ferdowsi University of Mashhad and Western Sydney University. We wish to express our sincere thanks to them for providing the opportunity for us to do this project.

\section{References}

Cameron, R. (2010). Mixed Methods Research: The Five Ps Framework. The Electronic Journal of Business Research Methods, 9, 96-108. www.ejbrm.com

Churchland, P. (2002). Brain-wise: Studies in neurophilosophy. https://books.google.com/ books?hl=en\&lr=\&id=vGY1BkA-gyYC\&oi=fnd \&pg=PP7\&dq=Brain-wise:+Studies+in+neurophilosophy:+MIT+press.\&ots=td5APok91P\&sig=pYL1jTp6GUz5AHFMZ_LEVlzdUQA

Clark, A., \& Chalmers, D. (1998). The extended mind. Analysis, 58(1), 7-19.

Creswell, J.W. (2011). Controversies in mixed methods research. The Sage Handbook of Qualitative Research, 4, 269-284.

Descartes, R., \& Cress, D.A. (1998). Discourse on method. Hackett Publishing ; and: Meditations on first philosophy. $4^{\text {th }}$ ed. Indianapolis: Hackett publishing.

Ehrenfeld, J. (2008). Sustainability by design: A subversive strategy for transforming our consumer culture. Yale University Press.

Goldstein, J. (1999). Emergence as a construct: History and issues. Emergence, 1(1), 49-72.

Hallowell, R. (2009). Humberto Maturana and Francisco Varela's contribution to media ecology: Autopoiesis, the Santiago School of Cognition, and enactive cognitive science. Proceedings of the Media Ecology Association, 10, 144-158.

Kyselo, M. (2014). The body social: an enactive approach to the self. Frontiers in Psychology, $5,986$.

Lutz, A. (2002). Toward a neurophenomenology as an account of generative passages: A first empirical case study. Phenomenology and the Cognitive Sciences, 1(2), 133-167.

Lutz, A., \& Thompson, E. (2003). Neurophenomenology integrating subjective experience and brain dynamics in the neuroscience of consciousness. Journal of Consciousness Studies, 10(9-10), 31-52. 
Malkemus, S.A. (2012). Toward a General Theory of Enaction: Biological, Transpersonal, And Phenomenological Dimensions. Journal of Transpersonal Psychology, 44(2).

Maturana, H.R., \& Varela, F.J. (1980). Autopoiesis: The organization of the living. Autopoiesis and Cognition: The Realization of the Living, 42, 59-138.

Maturana, H.R., \& Varela, F.J. (1987). The tree of knowledge: The biological roots of human understanding. New Science Library/Shambhala Publications.

Mingers, J. (2001). Combining IS Research Methods: Towards a Pluralist Methodology. Information Systems Research, 12(3), 240-259. https://doi.org/10.1287/isre.12.3.240.9709

Onwuegbuzie, A.J., \& Collins, K.M.T. (2007). A Typology of Mixed Methods Sampling Designs in Social Science Research. The Qualitative Report, 12(2), 281-316. http://www. nova.edu/ssss/QR/QR12-2/onwuegbuzie2.pdf

Rowlands, M.J. (2010). The new science of the mind: From extended mind to embodied phenomenology. MIT Press.

Rudrauf, D., Lutz, A., Cosmelli, D., Lachaux, J.-P., \& Le Van Quyen, M. (2003). From autopoiesis to neurophenomenology: Francisco Varela's exploration of the biophysics of being. Biological Research, 36(1), 27-65.

Shabani Varaki, B., Floden, R.E., \& Javidi Kalatehjafarabadi, T. (2015). Open Review of Educational Research Para-quantitative Methodology: Reclaiming experimentalism in educational research. Review of Educational Research, 2(1), 26-41. https://doi.org/10.1 080/23265507.2014.986189

Stewart, J., Gapenne, O., \& Di Paolo, E.A. (2010). Enaction: Toward a new paradigm for cognitive science. MIT Press.

Thompson, E. (2005). Sensorimotor subjectivity and the enactive approach to experience. Phenomenology and the Cognitive Sciences, 4(4), 407-427.

Thompson, E. (2007). Mind in life: Biology, phenomenology, and the sciences of mind. Cambridge, MA, US. Belknap Press/Harvard University Press.

Varela, F.J. (1996). Neurophenomenology: A methodological remedy for the hard problem. Journal of Consciousness Studies, 3(4), 330-349.

Varela, F.J. (1997). Patterns of life: Intertwining identity and cognition. Brain and Cognition, 34(1), 72-87.

Varela, F.J., Thompson, E., \& Rosch, E. (2016). The embodied mind: Cognitive science and human experience. MIT press.

Wilson, R.A., \& Foglia, L. (2011). Embodied cognition. In Stanford Encyclopedia of Philosophy, Stanford University Press. 